\title{
LA UNIVERSIDAD, REALIDAD PROBLEMÁTICA
}

Julián Marías (*)

La Universidad de San Marcos de Lima me pide unas palabras sobre "La Universidad en el siglo XX". La ocasión, su cuarto centenario. El motivo, la conciencia que tienen todas las cabezas claras que se mueven en torno a la Universidad, de que ésta no es hoy nada sencillo y obvio, que pueda marchar sin más y hacer lo mismo que hasta ahora. La Universidad de San Marcos de Lima es la más antigua de las dos Américas: a los cincuenta y nueve años del descubrimiento, una Universidad se levantaba ya junto a los bordes del Pacífico. Soy poco amigo del énfasis, y no suelo envanecerme con glorias pretéritas españolas ni hispanoamericanas; temo, más bien, todos esos grandes gestos que suelen hacer las gentes de nuestro linaje; pero tampoco creo que se deba pasar por alto el shock que en nuestra sensibilidad histórica produce esa fecha: | $55 \mid$. Y esa ya larga tradición de cuatro siglos de autoridad a la Universidad de Lima para preguntarse hoy qué pasa con la Universidad. iTendré yo alguna autoridad para intentar dar una respuesta? Esto es más que problemático.

Porque ocurre que yo no pertenezco a ninguna Universidad. Toda mi relación con la de Madrid ha sido de alumno; toda mi docencia ha sido al margen de la Universidad -salvo fugaces contactos como invitado, en España o fuera de ella-. Esta condición personal mía, ino me descalifica para hablar de la Universidad? Así lo creería si no me sintiese profundamente universitario; si no pensara además que la misión del pensamiento es sacar partido de lo negativo, de las limitaciones, sobre todo de las privaciones. ¿Por qué no intentar extraer las raíces transindividuales - sociológicas, históricas, intelectuales- de mi condición de universitario fuera de la Universidad, en esta precisa fecha de 1951?

\section{LAS VICISITUDES DE LA UNIVERSIDAD}

Universidades en un sentido próximo al actual, al menos lo bastante para que se pueda considerar unitariamente su historia, existen desde hace algo más de setecientos años. La institución universitaria ha experimentado a lo largo de ese tiempo graves vicisitudes; no me refiero, claro es, al esplendor o decadencia de cada una de ellas, ni siquiera a la prosperidad general o al descenso de nivel, sino a algo más importante: la función que las Universidades han ido asumiendo. Por lo pronto, se ocurre la división más gruesa y elemental: ha habido épocas en que la 
Universidad ha coincidido aproximadamente con la vida intelectual; en otras, por el contrario, ha sido sólo un componente parcial de ella, y lo más vivo y creador del pensamiento ha transcurrido al margen. Antes de preguntarnos si estamos en una época de las primeras o de las segundas, y -lo que se me antoja más interesantesi avanzamos hacia una u otra, conviene tener presente cómo ha sido el mundo cuando la Universidad ha sido casi toda la vida intelectual y cuando ha sido sólo una modesta porción de ella.

Lo primero ocurre, como es notorio, en la Edad Media, sobre todo en los siglos XIII y XIV; claro está que esto sólo es cierto si introducimos una restricción: si consideramos como vida intelectual en sentido estricto sólo la ciencia, es decir, la filosofía y la teología, las disciplinas cultivadas en latín por una minoría de pensadores, en su máxima parte monjes y frailes, cuya efectiva función dentro de la totalidad de la vida medieval está por precisar. Pero, teniendo en cuenta esta salvedad, es evidente que la ciencia de los últimos siglos de la Edad Media se hace en las Universidades, en ellas se enseña, ellas son, en definitiva, sus órganos y el ámbito en que existe y vive.

Otro es el caso entre mediados del XV y más que mediado el XVIII. En este tiempo, las Universidades quedan resueltamente relegadas a un segundo plano; lo más sustantivo de la ciencia europea se gesta en otros mundos. Santo Tomás, San Alberto Magno, Duns Escoto, Ockam -las figuras máximas del tiempo- habían sido docentes universitarios. No lo son, en cambio, Nicólas de Cusa, Erasmo, Giordano Bruno, Copérnico, Galileo, Descartes, Malebranche, Spinoza, Leibniz, Pascal, Bacon, Locke, Berkeley, Hume, Voltaire, D `Alembert, Rousseau... Todavía lo son Vitoria o Suárez, por que pertenecen a la forma medieval del saber y de la ciencia, aunque sus problemas y sus contenidos sean modernos en buena parte.

Las cosas vuelven a cambiar. Tal vez la variación se inicia con Wolff, el nuevo escolástico. Después si: los grandes creadores del pensamiento suelen ser profesores de Universidad: Kant, Fichte, Schelling, Hegel, Dilthey, Brentano, hasta Husserl y Bergson -para hablar sólo de la filosofía: sin esfuerzo se podría ampliar la lista en las restantes disciplinas-; los que no son universitarios están literalmente "desplazados": así Schopenhauer, Comte o Kierkegaard. Desde fines del siglo XVIII hasta los comienzos del nuestro, la ciencia se hace en las Universidades. Y el prestigio y el influjo social de ésas llegan a su máximo. ¿Por qué?

\section{La Universidad, Servicio público}

Creo que no se puede interpretar la Universidad desde el punto de vista exclusivo ni aún principal del saber, sino desde su función; y ésta es la de un servicio público -no forzosamente estatal, porque lo público no es sólo el Estado-. Por consiguiente, la suerte de la Universidad está íntimamente ligada a la de las demás instituciones; 
el hecho de que se ocupe de esa materia sutil que son las ideas no debe enturbiar el aspecto netamente institucional que le pertenece. La Universidad requiere, para funcionar bien y con normalidad, estar fundada en un sólido y compacto sistema de vigencias; cuando éstas fallan, la vida intelectual tiene que buscar formas más tenues, menos seguras, pero más flexibles y con menos obra muerta, más capaces de eludir los riegos y de inventar en cada hora su perfil. Me refiero, claro está, a todo orden de vigencias, y entre ellas incluyo las intelectuales: es muy difícil que en un momento de radical crisis de la ciencia, sobre todo de la idea del saber, el órgano capital del pensamiento pueda ser la Universidad. Esta reclama, con cimiento, un consensus acerca de todo lo decisivo: religión y ciencia, moral y esperanzas del hombre, poder y libertad, ordenación económica y papel de las clases sociales. Pero adviértase que el consensus a que me refiero no implica unanimidad y acuerdo respecto a los contenidos, sino acerca de la función efectiva en la vida. Por ejemplo, no puede hablarse de un consensus positivo en la vida religiosa europea del siglo XIX; pero la vigencia dominante entonces era que se podría opinar cualquier cosa en materia religiosa, que no importaba la discordia, y en ese no importar radica la concordia de que aquí se trata. Por esta misma razón, la Universidad no excluye la discusión: al revés, la exige, permite y realiza. Pero sería ingenuo pensar que la discusión revela hondo desacuerdo: al contrario, es la prueba de la concordia; por eso en los tiempos en que el desacuerdo es radical, se deja de discutir. La discusión termina cuando se llega al nego suppositum; florece sobre una base de supuestos comunes, a los que automáticamente se apela: piénsese en los dos máximos ejemplos de discusión: el escolasticismo y los parlamentos liberales del XIX. Cuando el desacuerdo es serio y radical, cuando no se sabe a dónde agarrarse, se deja de disputar, porque todo es demasiado grave, no hay terreno común en qué poner el pie y se contesta a las razones, como decía el Dante, con un cuchillo.

Desde este punto de vista parecen claras las vicisitudes de la Universidad europea: en la Edad Media, la Universidad es uno de los tres órganos del "pouvoir spirituel" que tan agudamente estudió Comte, con el Pontificado y el imperio -que sólo era en rigor poder espiritual-; desde el Renacimiento, en cambio, esa estructura se agrieta y resquebraja; empieza la era de las innovaciones radicales -en filosofía, en religión, en arte, en ciencia, en política, en economía, en la imagen física del mundo-; y la Universidad se resiente de ello, se queda al margen de lo más grave que ocurre, se queda "penúltima", si vale la expresión; frente a la Soborna, el Colegio de Francia; y más aún la estufa solitaria de Descartes, el cuarto donde Spinoza pule cristales, el pesado coche donde Leibniz, por los caminos de Europa, divierte las horas de lento traqueteo con divinas minucias: monadas y infiniment petits.

Sólo el enorme prestigio social de los ilustrados, de los enciclopedistas, devuelve vigencia y fuerza casi institucional al pensamiento: a fuerza de philosophes adquiere 
peso en la sociedad la filosofía. No se ha solido reparar en que Voltaire, D'Alembert o Diderot hacen posible la figura social del maestro Kant, que puede ser, hasta la raíz, profesor de la Universidad de Königsberg; y hasta aquel viento apasionado y encendido que se llamó el idealismo alemán que puede soplar en las apacibles Universidades tudescas, junto a un río manso y un bosque de castaños y casas de tejados puntiagudos, que saludan respetuosas al Señor Profesor: Jena, Würzburg, Tübingen, Munich, Heildelberg.

En el siglo XIX -el más seguro de la historia moderna-, la ciencia adquiere algo decisivo: una mayúscula; y la Ciencia se avecinda en la universidad, que es ahora, plenamente, servicio púbico en su forma más estricta: asunto del Estado, y del Estado en su fase de prepotencia y eficacia. El profesor universitario tiene detrás de sí toda la fuerza y la estabilidad de la Constitución, el Parlamento, los Tribunales, la Sanidad; es, en el pleno rigor del término, un funcionario, con toda su dignidad y toda su limitación. Esta situación dura hasta 19 |4; pero, por desdicha o por fortuna, pertenece al pasado. ¿Cuál es la nuestra? Contestar a esa pregunta requiere anteponerle otra: ¿qué es la Universidad?

\section{Cuatro funciones}

La Universidad es, repito, un servicio público; pero su misión no es simple, sino bastante compleja; por lo menos, cuádruple; se pueden distinguir perfectamente cuatro funciones bien distintas de la Universidad actual. Distintas, pero a su vez -y esto es lo más grave, lo decisivo- conexas; por eso digo que su misión es compleja, no sólo compuesta de cuatro funciones cuando los demás están en crisis.

Se podrían enumerar así -sin demasiada precisión- las funciones universitarias en nuestro siglo:

I) Función en la vida intelectual creadora.

2) Función docente.

3) Función social en cada país.

4) Función de relación internacional.

Será menester explicar, siquiera en pocas palabras, estos cuatro aspectos de la realidad universitaria en nuestros días.

I) He rehuido la expresión tradicional "investigación", porque creo que se trata de algo más rico y profundo. La palabra investigación está demasiado cargada de resonancias de laboratorio o de seminario filológico; es decir, pesa en ella 
excesivamente el aspecto "técnico" del trabajo, la idea de "taller". Con demasiada frecuencia, la "investigación" no es más que el sucedáneo de lo que llamo vida intelectual creadora. Esta es el contacto vivo con los problemas más vivos, el funcionamiento de la actividad intelectual ejercitada en toda su desnudez, la exposición de un pensamiento que se está haciendo, la convivencia real de maestros y discípulos, es decir, el encuentro efectivo de varias generaciones en las cosas mismas, en la fricción sobre los mismos problemas. Esta función no es la más característica de la Universidad, ni la de mayor volumen; se puede ejercer fuera de ella, y a pesar de su ausencia suelen marchar más o menos las universidades; pero es la que vivifica todas las demás.

2) La docencia es el torso general de la Universidad. Propiamente, consiste en eso; todo el resto es lo que hace posible la docencia, lo que la completa, sus consecuencias y efectos. Ahora bien, se plantean dos problemas que no carecen de conexión. Uno, es del nivel de esa docencia; ihasta qué punto la ciencia que enseña en las Universidades del mundo actual es actual, quiero decir, está a la altura de los tiempos? ¿En qué medida pueden hoy las Universidades innumerables que existen en el mundo enseñar de verdad -en filosofía, en filología, en historia, en física, en biología- lo que es hoy cada una de esas disciplinas, y no un remedo o caricatura? Y en el caso de las ciencias que son un puro problema, cuya crisis es gravísima y de principios - para tomar dos ejemplos cuya disparidad sea máxima, la lógica y el derecho- icómo puede realizarse la docencia, y dónde, quiero decir, en cuántas Universidades?

3) Llamo función social de la Universidad en cada país al papel que represente dentro de la vida nacional en su conjunto. No a los actos concretos que la Universidad ejecute de puertas fuera -"extensión universitaria", conferencias, congresos, etc.-, sino a los efectos nacionales del funcionamiento intrínseco de la Universidad en su vida propia. Estos efectos son enormemente variables de un país a otro, de éste o aquel decenio. Y son muy diversos; un influjo hormonal, de excitación intelectual de la sociedad entera; una catálisis en que la Universidad, sin intervención activa, provoca y hace posibles determinadas reacciones del cuerpo social; una influencia tranquilizadora, que produce seguridad, cuando se cree que hay quien se ocupe de los problemas, que hay un organismo cuya misión es plantearlos y resolverlos, que las cuestiones que tienen una vertiente intelectual están "en buenas manos", como la sanidad en una buena Medicina o la seguridad en una Policía eficaz; una función, por último, de prestigio, de conciencia nacional, de expresión del país entero por medio de sus órganos universitarios. ¿Cuál es el estado actual de esta función social en los diversos países? Nadie veraz se sentirá tranquilo. No puedo aquí, claro está, entrar en detalles, pero volveré en seguida sobre este punto. 
4) Desde hace ya muchos años, Europa es una en varias dimensiones; desde luego, en la intelectual. En ésta, no sólo se trata de Europa: en los últimos tiempos, la ciencia se hace en colaboración y, sobre todo, en presencia de todos -y en la medida en que no ocurre así no es eficaz, es decir, no es ciencia-. La vida intelectual es, pues, supranacional por una exigencia intrínseca, no por vano cosmopolitismo. Y por eso le pertenece necesariamente una expresión adecuada, cuyo órgano normal son las Universidades. El mundo actual es sobrado complejo para que pueda abandonarse a la inspiración de los individuos; la cantidad y el coste de todo hace utópico el confiar en lo que, por otra parte, es decisivo: la iniciativa individual. Sin instituciones, el diálogo internacional es quimérico. Pero se ocurre preguntar hasta qué punto el diálogo de que la institución es truchimán es real y no ficticio, hasta qué punto se consiguen por esta vía presencias reales y no espectrales alucinaciones. Esta es una grave cuestión, y en ningún lugar más oportuno plantearla que con ocasión de una colaboración internacional en torno al tema.

Pero esta gravedad es una prueba de que, en efecto, a la Universidad le pertenece esencialmente esa función supranacional, que sin ella no puede realizarse, aunque sea problemático que con ella se realice.

Y con esto llegamos a la verdadera cuestión: iqué ocurre en 1951 con esas cuatro funciones cuya interacción constituye la Universidad?

\section{Universidad, universalidad}

Volvamos a nuestro doble punto de partida: la Universidad es un servicio público; la Universidad está condicionada por la estructura del mundo como repertorio general de vigencias de todo orden, incluso -pero no solo- intelectual. Y, ante todo, un hecho cuantitativo, pero cuya significación es estrictamente cualitativa: las Universidades aparecen como dotadas de cierta doble universalidad: la primera, que pretenden abarcar la totalidad del saber; la segunda, que las hay en todas partes. Examinemos una tras otra ambas dimensiones.

Ya se que el sentido originario de universitas no alude a las disciplinas, sino a los miembros docentes y discentes: universitas magistrorum et scholarium. Pero no conviene quedarse enredado en la etimología -ni en filosofía ni en historia-; algunas de las mejores cabezas europeas han pagado con error un apego excesivo a lo que, usado discretamente y con libertad, es esencial. Junto a ese sentido etimológico, está vivo en el uso de la palabra Universidad el de totalidad de las ciencias: Panepistemion llaman a su Universidad los griegos actuales. Las de todo el mundo pretenden enseñar aproximadamente todo el globus intellectualis; y cuando les falta algún Facultad, se consideran "incompletas". 
En segundo lugar, la Universidad es una institución universal, difundida por todo el mundo en número crecidísimo: no hace muchas semanas vi un impresionante anuario o repertorio de las Universidades del mundo, y confieso que me sobrecogió. El supuesto de la Universidad actual es, por tanto, que se puede enseñar todo en todas partes. Los supuestos se suponen y se callan; no cabe duda que este, así enunciado en forma concisa, es más que alarmante.

Al instante se ve que la Universidad es, irremediablemente, una utopía. Con lo cual no está condenada, porque casi todo lo que hombre hace es utópico -Ortega lo ha mostrado temáticamente-, pero si nos comprometemos a ponerla en su perspectiva justa y a no tomar demasiado el pie de la letra la realidad de su pretensión. Si esto se hiciera en serio, automáticamente quedaría saneada la situación y empezarín a andar mejor las cosas. Como pasó en economía el día que se reconoció que no se puede pagar en oro a la pesetas, pesos, francos o libras que indica el billete, y que la promesa de que el banco de tal país pagará al portador dicha suma es sólo... una manera de decir. Pero no puede eludirse la consecuencia negativa: se trata de un caso de inflación el carácter de servicio público que tiene la Universidad lleva consigo el que es, por lo pronto, un esquema social; es decir, que los "huecos" o "puestos" preceden a la realidad. No es que haya una ciencia y unos hombres capaces de enseñarla y unos jóvenes ansiosos de aprenderla, sino que lo que hay es unas Facultades, unas cátedras, unos seminarios, para los cuales se buscan titulares y discípulos. Recuerdo que hace quince años, un grupo de estudiantes de la Facultad de Filosofía y Letras de Madrid propusimos al Decano, D. Manuel García Morente, que estableciese una cátedra de Filosofía de la Historia. El Decano nos miró sonriente y nos dijo: "Díganme ustedes quién puede desempeñarla bien y en serio; si me lo proponen, aunque no sea ni bachiller lo traigo y le encargo un curso". Nos miramos, callamos, sonreímos también, agradecidos - nos había dado una lección que. Como se ve, todavía no he olvidado-, y nos marchamos pidiendo a Dios que nunca faltase esa prudencia.

Como, por desdicha, no sobra, el resultado es que una buena parte la Universidad es puramente irreal, aún en los países de más tradición y densidad intelectuales. Imagínese lo que ocurre en los pequeños países o en los países jóvenes, como son -para bien y para mal, como privilegio y como limitación- los americanos. Hay un mimetismo -en política, en economía, en la vida del pensamiento- que los lleva a reproducir automáticamente las estructuras que se consideran "nacionales", en lugar de preguntarse perentoriamente cuál es su realidad y hasta dónde son posibles. Creo hacer mejor obra a los países de Hispanoamérica con esta advertencia que con el halago en hueco que se suele verter sobre ellos, a bien poca costa. Pueden otros contemplar con admiración la proliferación de revistas filosóficas en algunos países hispanoamericanos, y todo lo que ese fenómeno lleva consigo; a mí me 
produce verdadero pavor, porque siempre he creído que la filosofía es asunto superlativamente minoritario, que ha hecho un puñado de hombres metidos en un rincón, en algunos países, en algunas épocas; y sé que casi ningún país de Europa puede hoy sostener de verdad más de una o dos revistas puramente filosóficas, y la inmensa mayoría ninguna, y a nada temo más que a eso que en español llamamos "hacer que hacemos".

La Universidad corre, por tanto, la suerte de todas las realidades sociales: no coincidir sino por excepción con su ser más auténtico. El gran número de Universidades y su amplitud hace imposible, a priori, su calidad suficiente. Hacen falta -se entiende, dados ciertos supuestos que son cualquier cosa menos evidente- tantos profesores, tantas cátedras, tantos seminarios, que una buena parte de ellos sólo pueden existir precariamente. Es algo análogo a lo que sucede con la interferencia de la pura vocación sacerdotal, que florece donde y cuando Dios quiere, y las perentorias necesidades del ministerio, de las misiones, de ciertas estructuras añadida y hoy por hoy sentidas como necesarias, la institución universitaria, desde el siglo XIX, ha cometido el mismo pecado que caracteriza a ese tiempo: confundir los deseos con la realidad, creer que lo plausible es posible, que se pueden prolongar indefinidamente las cosas. Creo que si la Universidad quiere conservar su misión a la vez creadora y rector $-\mathrm{o}$ lo que es lo mismo, si quiere subsistir-, ha de ser implacable consigo misma, ha de estar dispuesta a todas las renuncias, a todos los sacrificios. El día que vea que se renuncia a la existencia de muchas Universidades o de grandes porciones de ellas, empezaré a creer en la existencia de la Universidad.

\section{La vida pública}

Pero todo esto no es sino penúltimo. No se piense que voy a eludir el problema decisivo. Y éste es el de las conexiones de la Universidad, servicio público, con la vida púbica de nuestros días. Los peligros de esa relación estrecha son tan grandes como notorios; pero voy a decir algo más: son también universales. Conviene no hacerse ilusiones, no pensar que se trata de una situación que aqueja a la universidad en algunas naciones excepcionales. El hecho de que en algunos casos la intervención del Estado y la anomalía de la vida pública sean más llamativos que lo habitual no debe encubrir otro hecho mucho más grave: la generalidad de la situación. Hace poco he escrito en un ensayo que ha aparecido en París que la coacción, la falta de libertad, la contrainte está hoy casi tan bien repartida como el bon sens en el tiempo de Descartes. Las formas de esa contrainte son múltiples y variadas, desde las más toscas hasta las más indirectas y sutiles. Pero en todo caso hay presiones sociales, politicismo, selección imperfecta, orientaciones impuestas -no importa que la violencia no siempre se manifieste- que perturban la función intelectual y la convivencia universitaria. Esta situación puede llegar a excluir la participación en la vida universitaria de quien sea responsable y no esté dispuesto a admitir los modos deficientes de las cosas; pero 
en los casos mejores y más leves basta para producir un malestar, una inquietud que revela el carácter problemático de la institución universitaria. Esas renuncias y esta inquietud no son demasiado frecuentes; lo cual prueba sólo hasta qué grado está atenuada hoy en el mundo la conciencia de lo que es vida intelectual.

La vida púbica, por faltarle hoy sus posibilidades más propias, se extravasa continuamente fuera de sí misma. En Europa, los Estados nacionales tienen que habérselas con problemas que en su gran mayoría no son nacionales, sino europeos; por tanto, no pueden actuar de un modo eficaz y normal. Al no poder hacer política sensu stricto -la vida nacional de los países europeos ha perdido su "argumento", y esto es de lo más grave que puede pasar-, hacen por supuesto muy mal- todo género de otras cosas; y entre ellas diversos remedos de vida intelectual doméstica. En América, las cosas son distintas de las europeas, y distintas también de unos países a otros. Si dejamos de lado los Estados Unidos - de los que me falta información suficiente, y no quisiera pecar por donde suelen nuestros contemporáneos: creer que lo saben todo-, es evidente que los países hispanoamericanos están amenazados siempre por un gravísimo quid pro quo: en vista de que son Estados soberanos y de que los Estados soberanos europeos han solido ser naciones -repárese en el subrayado-, se consideran a sí mismos como naciones sin más; y no advierten que la nación es una forma muy concreta de unidad histórica, que no siempre ha habido, sino quizá solo en Europa desde el siglo XVI hasta el XIX -hoy ya es crisis-, y que es sumamente problemático que en América haya habido ni haya nunca naciones, si tomamos esta palabra en serio y le damos un significado histórico preciso. Tomar con unidades "homogéneas", que se pueden sumar y restar a Francia y El Salvador, Alemania y el Brasil, España y Bolivia, la Argentina y Holanda, me parece tan incoherente y peligroso como hacer otro tanto con Egipto durante el Imperio medio y la Atenas de Solón, el Califato de Omar y Borgoña, el Imperio de los Incas y el Condado de Castilla, Cartago y Bizancio.

En la situación de la vida pública actual, ninguna institución puede funcionar de suyo y sin problemas: ni el Ejército, ni la Justicia, ni la Monarquía, ni el Parlamento; iiba a ser una excepción la Universidad, más delicada que ninguna otra institución, porque tiene que fundir su vertiente social con las exigencias de la materia más vidriosa del mundo?

\section{Formas nuevas}

No necesito decir, al llegar a este punto, que para mí la universidad ha pasado su hora mejor, que tal vez nunca vuelva a recobrar su plena sazón; en suma, que la Universidad es hoy, en cierta medida, arcaica. Sólo penosamente puede ejercer las cuatro funciones en cuya interacción consiste; y es notorio que la primera y más íntima se realiza en su máxima parte al margen de la Universidad. 
Todo ello aconseja imperiosamente la invención y el ensayo de formas nuevas de vida intelectual, de trabajo común de docencia incluso. Formas más sueltas y libres, más pobres, con menos peso muerto, con menos obligaciones externas y, por consiguiente, con mayor capacidad de exigencias íntimas. Estas nuevas posibles instituciones habrán de ser, desde luego, pocas; en segundo lugar, inseguras; en tercer lugar, parciales y dedicadas a ciertos temas concretos; y si quieren ser, insobornables y, por tanto, nunca prósperas. Perpetúas aventuras, en lo intelectual y en su menguada figura social.

Sólo a ese precio podrán ser fecundadas. Es posible que logren vivificar el mundo del pensamiento, que hagan a algunos grupos de hombres, aquí y allá, tropezar de nuevo con esa faena dramática y arriesgada que llamamos pensar. Su papel será el de fermentos -algunas veces son reminiscencias de catacumbas-.

Pero si se trata de aforar el volumen de su eficacia, surgen graves dudas. No tanto por lo que pueda tener de reducida su esfera de acción, sino por otras razones más complejas. llustraré lo que quiero decir con un ejemplo. La experiencia de los últimos cinco o seis años en España aporta datos singularmente valiosos. En estricta forma privada, sin intervención estatal, sin apoyos de ningún orden, sin la menor base económica, se han iniciado actividades de orden intelectual de las que tal vez se hable largo en su día. Me refiero a los cursos privados que desde hace un quinquenio explica Zubiri, a los cursos, coloquios e investigaciones del instituto de Humanidades, fundado por Ortega y por mí en 1948, a algunos quehaceres íntimamente ligados con éstos. La eficacia de estos intentos es difícil de exagerar; su amplitud, también. A pesar de tratarse de cursos pagados, Zubiri ha reunido en torno suyo un auditorio fiel durante cinco años y siempre creciente, que ha llegado al centenar. Ortega empezó con 650 oyentes, que en el segundo curso fueron 1300. En la primavera pasada más de doscientas personas han seguido un curso, bastante ceñido, de filosofía, profesado por mí. Es decir, estas formas privadas de docencia congregan auditorios mucho mayores que los universitarios. Parece, pues, que la fórmula está hallada, y que no es menester preocuparse por la crisis de la Universidad. La vida intelectual ha encontrado por sí misma, se dirá, los modos de reemplazarla.

Creo que pensar esto sería un grave error. La misión de esas formas nuevas no puede nunca sustituir a la Universidad. Y esto por las razones antes enumeradas, es decir, precisamente por su carencia de esa peligrosa pero inevitable "universalidad". Muchas disciplinas no encontrarán nunca representación en esas nuevas instituciones o quasi-instituciones; aun las que la tengan, nunca en su integridad, sino en ciertos escorzos precisos, quizás los más fecundos e incitantes, pero parciales; sobre todo, esas instituciones, que no pueden existir sino en contados puntos del planeta, donde una constelación de esfuerzos y azares las haga viables, no se dirigen sino a ciertos grupos muy precisos, que no coinciden con los muchos hombres y mujeres que 
tienen que pasar por la Universidad. Estas instituciones deberán hacer lo que la Universidad no hace; no podrán hacer bien, en cambio, lo que está hace mal. Es la Universidad misma la que deberá ponerse en forma. ¿Es esto posible?

\section{Las posibilidades universitarias}

Al llegar a este punto, siento que empieza a faltarme la autoridad a que aludí al comienzo de estas páginas. Creo que puedo contentarme con haber planteado lealmente el problema; a otros corresponde buscar la solución. Quisiera, sin embargo, decir todavía una palabra. No conozco otro modo de resolver los problemas a partir de ellos; la única manera de superar las dificultades es apoyarse precisamente en ellas para brincar hacia lo alto. Por esto, lo que más urge a la Universidad es penetrarse de su condición problemática. Sólo es posible hoy ser universitario con cierta intranquilidad, yo diría hasta de conciencia. Esa inquietud puede ser salvadora; su primera consecuencia es evitar la inercia, el hacer lo de siempre, como si estuviese justificado y fuese obvio; la segunda, eliminar la petulancia y la fácil satisfacción, para sustituirlas por lo más importante, que no sabe bien qué tiene que hacer, que su misión es más que dudosa; y realizarla con una orgullosa modestia. Sólo es posible que la Universidad esté en forma mediante un complicado sistema de renuncias: a su existencia en muchos casos, a grandes trozos de sí misma en otros, a todas las funciones que en rigor no puede ejercitar, a todas las ventajas - por ejemplo, sociales, políticas y económicas- que le vienen de existir en huevo o de su conformismo: con el Estado o con la oposición -que también puede ser conformismo-.

Pero, de un modo o de otro, la misión de la Universidad es indeclinable. Tal como está el mundo, tiene que haber Universidades, sólo en ellas puede enseñarse y aprenderse el sistema de ideas de la época, puede adquirirse la formación profesional, puede realizarse la educación de la "inmensa minoría". Frente a todas las dificultades, esta conciencia puede ser confortadora: por eso hablaba unas líneas más arriba de orgullosa modestia. ¿No es una empresa digna de la Universidad, de su gloriosa historia de siete siglos, recrearse de nuevo en estas estrechas circunstancias? La Universidad está entre la espada y la pared: la mejor situación para luchar. Y entonces conviene reivindicar, en todas sus formas, la condición de universitarios. Lo somos todos los que hemos sido informados y conformados por la Universidad, los que pertenecemos para siempre a aquella universitas magistrorum et scholarium, sea cualquiera el lugar donde nos sitúe la forma auténtica de esa pertenencia. 


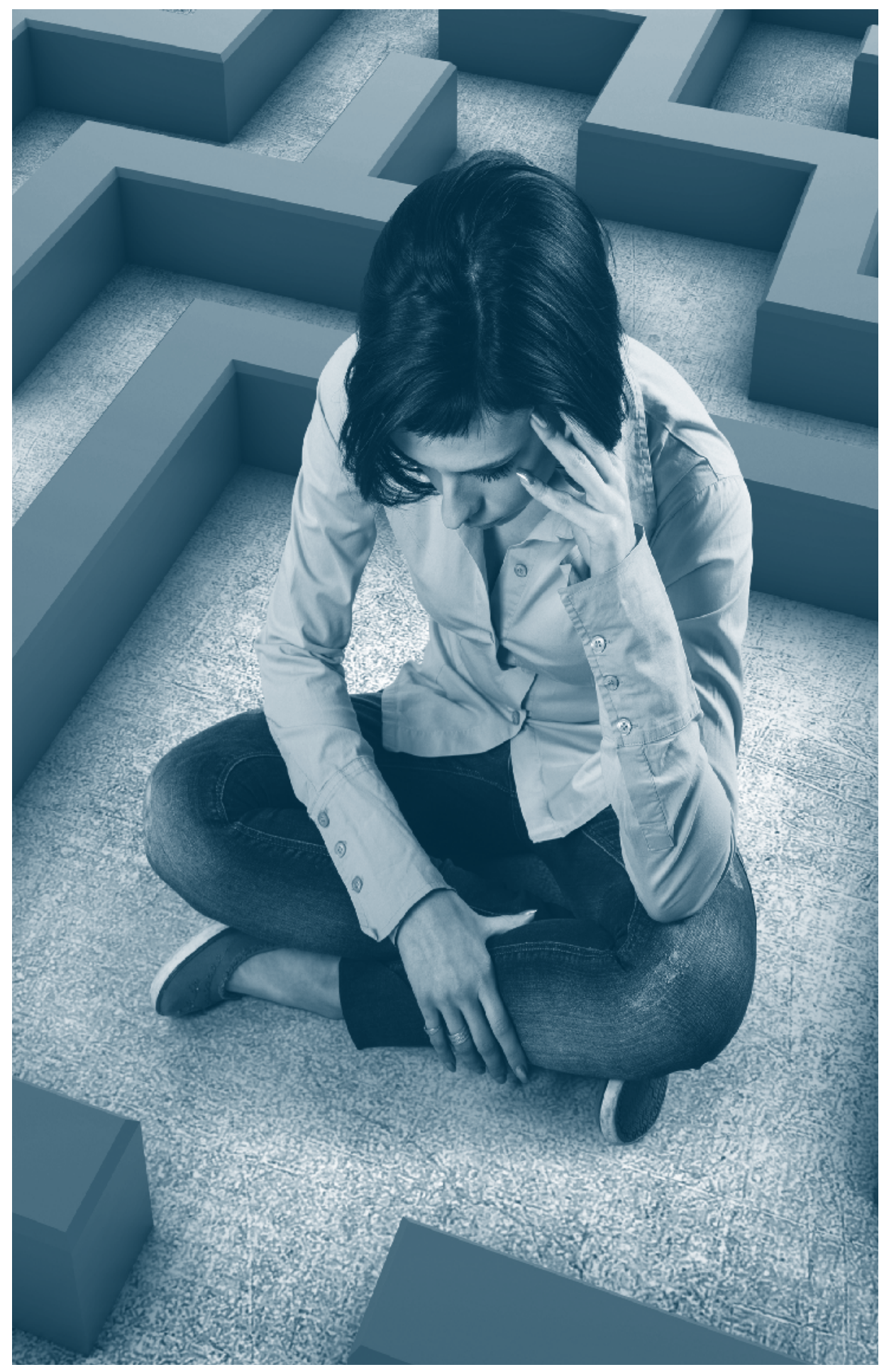

